\title{
Endogenous Opioid Activity in the Anterior Cingulate Cortex Is Required for Relief of Pain
}

\author{
DEdita Navratilova, ${ }^{1}$ Jennifer Yanhua Xie, ${ }^{1}$ Diana Meske, ${ }^{1}$ Chaoling $Q u,{ }^{1}$ Kozo Morimura, ${ }^{1}$ Alec Okun, ${ }^{1}$ \\ Naohisa Arakawa, ${ }^{1}$ Michael Ossipov, ${ }^{1}{ }^{-}$Howard L. Fields, ${ }^{2}$ and Frank Porreca ${ }^{1}$ \\ ${ }^{1}$ Department of Pharmacology, Arizona Health Sciences Center, University of Arizona, Tucson, Arizona 85724, and ${ }^{2}$ Department of Neurology, University of \\ California, San Francisco, San Francisco, California 94143
}

\begin{abstract}
Pain is aversive, and its relief elicits reward mediated by dopaminergic signaling in the nucleus accumbens (NAc), a part of the mesolimbic reward motivation pathway. How the reward pathway is engaged by pain-relieving treatments is not known. Endogenous opioid signaling in the anterior cingulate cortex (ACC), an area encoding pain aversiveness, contributes to pain modulation. We examined whether endogenous ACC opioid neurotransmission is required for relief of pain and subsequent downstream activation of NAc dopamine signaling. Conditioned place preference (CPP) and in vivo microdialysis were used to assess negative reinforcement and NAc dopaminergic transmission. In rats with postsurgical or neuropathic pain, blockade of opioid signaling in the rostral ACC (rACC) inhibited CPP and NAc dopamine release resulting from non-opioid pain-relieving treatments, including peripheral nerve block or spinal clonidine, an $\alpha_{2}$-adrenergic agonist. Conversely, pharmacological activation of rACC opioid receptors of injured, but not pain-free, animals was sufficient to stimulate dopamine release in the NAc and produce CPP. In neuropathic, but not sham-operated, rats, systemic doses of morphine that did not affect withdrawal thresholds elicited CPP and NAc dopamine release, effects that were prevented by blockade of ACC opioid receptors. The data provide a neural explanation for the preferential effects of opioids on pain affect and demonstrate that engagement of NAc dopaminergic transmission by non-opioid pain-relieving treatments depends on upstream ACC opioid circuits. Endogenous opioid signaling in the ACC appears to be both necessary and sufficient for relief of pain aversiveness.
\end{abstract}

Key words: affective dimension of pain; anterior cingulate cortex; neuropathic pain; nucleus accumbens; postsurgical pain; reward

\section{Introduction}

Pain involves somatosensory, affective, and cognitive features. Human and animal studies have identified multiple brain regions, including the insula, prefrontal cortex, anterior cingulate cortex (ACC), amygdala, and dorsal and ventral striatum, involved in processing the affective component of pain (i.e., pain aversiveness; Leknes and Tracey, 2008; Becker et al., 2012; Bushnell et al., 2013). ACC activity is reported consistently after acute noxious stimulation (Apkarian et al., 2005) and is correlated with subjective unpleasantness (Rainville et al., 1997). The ACC receives nociceptive input from the spinal cord via the thalamus (Vogt and Sikes, 2000). ACC neurons show wide bilateral receptive fields and long-lasting responses to noxious stimulation (Wang et al., 2003). Microinjection of excitatory amino acids into the rostral ACC ( $\mathrm{rACC}$ ) of uninjured rats produces conditioned

\footnotetext{
Received Sept. 16, 2014; revised March 16, 2015; accepted March 31, 2015.

Author contributions: E.N., H.L.F., and F.P. designed research; J.Y.X., D.M., C.Q., K.M., A.O., and N.A. performed research; E.N., J.Y.X., D.M., C.Q., K.M., A.O., and M.O. analyzed data; E.N., H.L.F., and F.P. wrote the paper.

This work was supported by National Institutes on Drug Abuse Grant DA034975 (F.P.). K.M. was a visiting scholar from Mitsubishi Tanabe Pharma, N.A. was a visiting scholar from Daiichi Sankyo, and A.0. is a postdoctoral fellow supported by a Lilly Innovation Fellowship Award. We gratefully acknowledge the technical assistance of Janice Oyarzo, Xu Yue, and Dong Lu.

The authors declare no competing financial interests.

Correspondence should be addressed to Dr. Frank Porreca, Department of Pharmacology, University of Arizona, Tucson, AZ 85724. E-mail: frankp@u.arizona.edu.

DOI:10.1523/JNEUROSCI.3862-14.2015

Copyright $\odot 2015$ the authors $\quad 0270-6474 / 15 / 357264-08 \$ 15.00 / 0$
}

place aversion without altering sensory thresholds (Johansen and Fields, 2004). In contrast, rACC lesion abolishes pain-induced aversive behavior without altering acute evoked behavioral pain responses (Johansen et al., 2001; LaGraize et al., 2004; Qu et al., 2011). Thus, excitatory neurotransmission in the ACC produces a teaching signal that is necessary and sufficient for nociceptive aversiveness.

The ACC is also involved in pain modulation (Bushnell et al., 2013). Emotional states affect pain unpleasantness, and the magnitude of this effect often correlates with altered pain-evoked ACC activations (Villemure and Bushnell, 2009). ACC activations have been demonstrated during placebo-induced analgesia (Wager et al., 2004), with termination of a prolonged noxious stimulation (Becerra et al., 2013) and after relief of neuropathic pain (Hsieh et al., 1995; Willoch et al., 2003).

Opioids are used widely for the treatment of persistent pain and have been suggested to act within brain circuits, including the ACC, to primarily modulate pain affect (LaGraize et al., 2006; Oertel et al., 2008). High levels of opioid receptors are expressed in rostral regions of the ACC (Vogt, 2005). In humans, activation of endogenous opioids in the ACC has been shown during placebo analgesia (Wager et al., 2007; Zubieta and Stohler, 2009) and during sustained experimental pain (Zubieta et al., 2001). A positive correlation between pain-induced ACC endogenous opioid activation and reduced affective aspects of pain was found ( $\mathrm{Zu}-$ bieta et al., 2001). 
Relief of ongoing pain, like relief of other aversive states, is rewarding. In animals, relief of pain aversiveness promotes learning and motivation to seek a context associated with relief (negative reinforcement) that can be assessed by conditioned place preference (CPP) (King et al., 2009; Navratilova et al., 2013). In rats with ongoing postsurgical pain, peripheral nerve block (PNB) produced CPP and elicited dopamine (DA) release in the nucleus accumbens (NAc; Navratilova et al., 2012). Additionally, CPP and NAc DA release has been shown in rats with neuropathic pain after intrathecal clonidine, an $\alpha_{2}$-adrenergic receptor agonist (Xie et al., 2014). We hypothesized that the relief of ongoing pain requires opioid signaling in the rACC and subsequent downstream activation of DA neurotransmission in the NAc mediating the reward of pain relief. Additionally, we explored whether opioid activation of ACC underlies reward of pain relief (Leknes et al., 2011) after systemic opioid administration.

\section{Materials and Methods}

Animals. Male Sprague Dawley rats (250-350 g; Harlan Laboratories) were housed on a $12 \mathrm{~h}$ light/dark cycle with food and water ad libitum. Procedures were conducted such that the number of animals and animals' suffering was minimized. All experiments were performed in accordance with policies and procedures set forth by the International Association for the Study of Pain and the National Institutes of Health guidelines for the handling and use of laboratory animals under approvals from the Institutional Animal Care and Use Committee of the University of Arizona.

Incisional injury pain model. Incision of the skin plus deep tissue, including fascia and underlying muscle, was performed as described previously (Brennan et al., 1996; Xu and Brennan, 2009, 2010). Rats were anesthetized with $2 \%$ isoflurane, and a $1 \mathrm{~cm}$ longitudinal incision was made through the skin of the left hindpaw to expose the muscle that was subsequently incised longitudinally. Incised skin was stitched with two 5-0 nylon sutures, and the wound site was treated with topical neomycin. Sham animals were anesthetized, and the left hindpaw was cleaned but no incision was made. Rats were tested $1 \mathrm{~d}$ after surgery.

Spinal nerve ligation pain model. As described previously by Kim and Chung (1992), the $\mathrm{L}_{5} / \mathrm{L}_{6}$ ligation was used to produce experimental chronic neuropathic pain. Rats were anesthetized with $2 \%$ isoflurane, and the lumbar vertebrae on the left side were exposed. The $\mathrm{L}_{5}$ and $\mathrm{L}_{6}$ spinal nerves were ligated tightly with 4-0 silk suture and the wound was closed. Sham-operated rats were prepared in the same manner except that the $\mathrm{L}_{5} / \mathrm{L}_{6}$ spinal nerves were not ligated. Rats were monitored for any visual signs of motor deficits and for general health and weight maintenance. Rats were tested 14-21 d after surgery.

Intracranial cannulation. Stereotaxic surgeries were performed in rats anesthetized with a ketamine $(80 \mathrm{mg} / \mathrm{kg}$; Western Medical Supply) and xylazine ( $12 \mathrm{mg} / \mathrm{kg}$; Sigma) mixture. Cannulas were implanted according to coordinates derived from the brain atlas of Paxinos and Watson (2007). A pair of 26 gauge guide cannulas in a single pedestal (Plastics One) was directed toward the NAc shell [anteroposterior (AP), bregma, $+1.7 \mathrm{~mm}$; mediolateral (ML), midline, $\pm 1.0 \mathrm{~mm}$; dorsoventral (DV), skull, $-6.5 \mathrm{~mm}$ ] or the rACC (AP, bregma, $+2.6 \mathrm{~mm}$; ML, midline, \pm 0.6 ; DV, skull, $-1.8 \mathrm{~mm}$ ). For NAc microdialysis, a single guide cannula (AG-8; Eicom) was implanted vertically into the left NAc shell (AP, bregma, $+1.7 \mathrm{~mm}$; ML, midline, $+1.0 \mathrm{~mm}$; DV, skull, $-6.0 \mathrm{~mm}$ ). For microdialysis studies requiring intra-rACC injections, bilateral 26 gauge guide cannulas (Plastics One) were implanted into the rACC at a $25^{\circ}$ forward-facing angle (AP, bregma, $+4.1 \mathrm{~mm}$; ML, midline, \pm 0.8 ; DV, $-3.0 \mathrm{~mm}$ ) together with the microdialysis NAc guide cannula. A single vertical 26 gauge guide cannula directed into the contralateral (right) rACC (AP, bregma, $+2.6 \mathrm{~mm}$; ML, midline, -0.6 ; DV, skull, $-1.8 \mathrm{~mm}$ ) together with the left NAc microdialysis cannula was used in experiments involving rACC morphine/saline. Stainless steel dummy cannulas were inserted into each guide to keep cannulas free of debris. After surgery, all animals were housed individually and allowed a minimum of $7 \mathrm{~d}$ to recover.
Intrathecal cannulation. Rats were anesthetized with a ketamine (80 $\mathrm{mg} / \mathrm{kg}$; Western Medical Supply) and xylazine (12 mg/kg; Sigma) mixture. The atlanto-occipital membrane was exposed, and a T-shaped incision was made in the dura mater. A length of polyethylene-10 tubing was filled with saline, and one end was heat sealed. A loose knot was made to leave an $8 \mathrm{~cm}$ length of tubing that was inserted into the vertebral canal and advanced to the level of the lumbar enlargement. The catheter was secured to the fascia and the wound was closed (King et al., 2012). The animals were allowed a minimum of $7 \mathrm{~d}$ to recover.

Brain microinjection. The injection cannulas (Plastics One) extended 1 $\mathrm{mm}$ beyond the end of the guide cannulas and were connected to a $2 \mu \mathrm{l}$ Hamilton syringe and driven by a syringe pump. Drug injections into the rACC or the NAc were given in a volume of $0.5 \mu \mathrm{l} /$ side at the following doses: naloxone hydrochloride ( $3 \mu \mathrm{g}$; Tocris Bioscience), morphine sulfate (20 $\mu$ g; National Institute on Drug Abuse), $\alpha$-flupenthixol dihydrochloride ( $3 \mu \mathrm{g}$; Sigma), or vehicle (saline). Dermorphin-saporin (DermSAP) or saporin (SAP; 1.5 pmol; Advanced Targeting Systems) were microinjected 28-32 d before experimentation directly into the rACC (AP, bregma, $+2.6 \mathrm{~mm}$; ML, midline, \pm 0.6 ; DV, skull, $-2.8 \mathrm{~mm}$ ) using a microinjector with a 33 gauge needle connected to a $2 \mu$ l Hamilton syringe. After each experiment, rats were killed with $\mathrm{CO}_{2}$ overdose, and $0.5 \mu \mathrm{l}$ of Black India Ink was injected into the rACC or NAc to verify cannula placement. Data from animals with misplaced cannulas were removed from analyses.

PNB. Lidocaine ( $4 \% \mathrm{w} / \mathrm{v}$; Roxane Laboratories) or saline (vehicle) was injected at a volume of $300 \mu \mathrm{l}$ into the popliteal fossa. This volume is sufficient to cover the sciatic nerve, including the peroneal, sural, and tibial branches (Kadiyala et al., 2005).

Intravenous drug administration. Animals received an intravenous injection of morphine sulfate $(0.25,0.5,1.0,2.0$, or $4.0 \mathrm{mg} / \mathrm{kg}$; National Institute on Drug Abuse drug supply program) dissolved in sterile saline. For evoked studies, intravenous morphine or saline was administered in animals placed in a restraining device. For CPP experiments, intravenous morphine or saline injections were done in rats that were lightly anesthetized with isoflurane ( $2 \%$ mixed with room air, $2 \mathrm{~L} / \mathrm{min}$ ). Animals typically awaken from anesthesia within $1 \mathrm{~min}$ while they are being placed in the paired chamber. Anesthesia was used to minimize stress associated with the intravenous injection. Importantly, anesthesia exposure neither increased (suggesting preference) nor decreased (suggesting aversion) time spent in the chamber in control animals. For microdialysis experiments, injections were done in awake animals that were restrained minimally by the experimenter $10 \mathrm{~min}$ before the start of experimental dialysate fraction collection.

Tactile and thermal hypersensitivity. Tactile hypersensitivity was tested using a series of calibrated von Frey filaments applied to the plantar aspect of the ipsilateral hindpaw. The up-down method was used to determine the 50\% withdrawal threshold with the Dixon nonparametric test as described previously (Chaplan et al., 1994). Thermal hypersensitivity (King et al., 2006) was determined using the method of Hargreaves et al. (1988). A noxious radiant heat source (i.e., high-intensity projector lamp) was directed onto the plantar surface of the left hindpaw, and the latency to the first escape response (i.e., jumping, licking, or climbing) was recorded. Experimenters were blinded to the treatment groups.

CPP. Experiments were conducted as described previously (King et al., 2009; Okun et al., 2011) using an unbiased conditioning protocol in which neither the apparatus (i.e., the CPP box) nor the procedure of animal assignment to the pairing chambers demonstrates preference before conditioning (Cunningham et al., 2003). On the preconditioning day (Day 1), rats were placed in the Place Preference System (San Diego Instruments) consisting of two pairing chambers with distinct sensory cues and a neutral middle chamber in which they had free access to all chambers for $15 \mathrm{~min}$ (i.e., $900 \mathrm{~s}$ ). Time spent in each chamber was automatically computed with the proprietary software. In some studies, rats were monitored in CPP boxes by video recorders, and the time spent in the chambers was determined with the ANY-Maze video tracking system (Stoelting). Rats that spent $>720 \mathrm{~s}$ or $<180 \mathrm{~s}$ in either testing chamber were excluded from the study (King et al., 2009; Okun et al., 2011). Animals were grouped to ensure no baseline chamber preference in each experimental group. On the morning of the conditioning day (Day 2), 
rats were injected with vehicle and immediately placed into the conditioning chamber for $30 \mathrm{~min}$; $4 \mathrm{~h}$ later, rats were administered the test drug and placed into the opposite conditioning chamber for $30 \mathrm{~min}$. Vehicle and drug administrations were performed under identical conditions. On the test day (Day 3), rats were placed in the CPP box with free access to all chambers for $15 \mathrm{~min}$, and the time spent in each chamber was recorded. Difference scores were calculated by subtracting the time spent in the drug-paired chamber of Day 1 (baseline) from that of Day 3 (testing).

In vivo microdialysis and DA quantification. Microdialysis experiments were done in awake and freely moving rats. Microdialysis probes (AZ-802 ; Eicom) were inserted into the guide cannula so that the $2 \mathrm{~mm}$ semipermeable membrane protruded from the guide into the NAc shell. The probe was perfused with artificial CSF (in mM: $147.0 \mathrm{NaCl}, 2.8 \mathrm{KCl}, 1.2$ $\mathrm{MgCl}_{2}$, and $1.2 \mathrm{CaCl}_{2}$ ) at a rate of $2.0 \mu \mathrm{l} / \mathrm{min}$ using a syringe, pump drive, and controller (MDN-0250, MD-1001, and MDN-1020, respectively; BASi). After a 75-90 min washout period, two baseline and four experimental fractions $\left(30 \mathrm{~min} /\right.$ fraction) were collected into prechilled $\left(4^{\circ} \mathrm{C}\right)$ Eppendorf tubes containing $1.5 \mu \mathrm{l}$ of $40 \times$ antioxidant solution $(6.0 \mathrm{~mm}$ L-cysteine, $2.0 \mathrm{~mm}$ oxalic acid, and 1.3\% glacial acetic acid; Hubbard et al., 2010). In some experiments, one baseline and one experimental fraction $(90 \mathrm{~min} /$ fraction) were collected. All rats were then injected with cocaine (20 mg/kg, i.p.), and dialysate was collected for an additional 60 min. Fractions were analyzed via an Agilent 1100 HPLC system coupled to an inline Coulochem III electrochemical detector with model 5011A analytical cell (E1, $-150 \mathrm{mV}$; E2, $+250 \mathrm{mV})$ and model 5020 guard cell (+350 mV; ESA; Acworth and Cunningham, 1999). Catecholamines were separated using an MD-150 analytical column $(3 \mathrm{~mm} \times 15 \mathrm{~cm})$ and MD-TM mobile phase (ESA) diluted to $9 \%$ acetonitrile, at a flow rate of $0.400 \mathrm{ml} / \mathrm{min}$. Agilent ChemStation data acquisition software was used to analyze the chromatograms. Posttreatment DA levels were expressed as percentage of each animal's baseline.

Immunohistochemistry. Rats with Derm-SAP or SAP lesions were transcardially perfused with PBS, followed by $4 \%$ paraformaldehyde. Coronal brain sections $(30 \mu \mathrm{m})$ were cut using a Microm HM 525 cryostat and mounted on Superfrost Plus microscope slides. Brain tissue was permeabilized with $0.2 \%$ Triton X-100, blocked with $5 \%$ normal goat serum plus $1 \%$ bovine serum albumin, and incubated overnight with rabbit polyclonal anti- $\mu$ opioid receptor (MOR) antibody (AOR-011; 1:20,000; Alomone Labs). The sections were incubated with biotinylated antirabbit antibody, followed by the $\mathrm{ABC}$ complex (Vectastain Elite $\mathrm{ABC}$ kit; Vector Laboratories) and tyramide signal amplification detection (TSA Plus Fluorescein Kit; PerkinElmer Life and Analytical Sciences). Slides were mounted in Vectashield mounting medium containing DAPI nuclear staining (Vector Laboratories) and examined under an Olympus BX51 microscope equipped with a Hamamatsu C8484 camera.

Statistical analysis. For CPP experiments, data are presented as difference scores [i.e., the difference between the time spent in the drug-paired chamber on Day 3 (testing) and on Day 1 (baseline)]. Previous experiments confirmed that the CPP procedure used is unbiased. Thus, a positive CPP score represents place preference, a negative score indicates aversion, and zero indicates no preference (Kuo and Yen, 2005; Mitchell et al., 2014). To evaluate significance $(p<0.05)$ of differences between the treatment groups, an unpaired $t$ test or a one-way ANOVA was used for two- or three-group comparisons, respectively. Two-way ANOVA was used to analyze experiments containing two variables. For microdialysis experiments, data were calculated as the percentage change from baseline. In those experiments in which four 30 min experimental fractions of dialysate were collected, the area under the time-effect curve (AUC) of percentage change from baseline was calculated, and the results were plotted as "AUC of \% change." In microdialysis experiments in which one $90 \mathrm{~min}$ baseline and one 90 min experimental fraction were collected, the percentage increase from baseline was calculated and plotted as " $\%$ baseline." Significance $(p<0.05)$ of the change in NAc DA levels was determined using ANOVA with Bonferroni's or Tukey's post hoc test when experiments contained three or more groups or Student's $t$ test for two-group comparisons. The numbers used, $p$ values, degrees of freedom, and $F$ ratios or $t$ scores were reported in Results. CPP and microdialysis measurements were performed in separate groups of ani- mals. Statistical calculations were made with GraphPad Prism 5.0 (GraphPad Software).

\section{Results}

\section{Reward from pain relief is dependent on opioid receptors in the rACC}

We first examined in rats with post-incisional or neuropathic pain whether rewarding effects of pain relief produced by nonopioid treatments would be prevented by inactivation of endogenous opioid neurotransmission in the rACC (corresponding to Brodmann areas 32 and 24). The CPP paradigm was used to assess the motivational drive of rats with ongoing pain to seek relief (negative reinforcement; King et al., 2009; Navratilova et al., 2013). When saline (vehicle) was microinjected in the rACC, relief of postoperative pain with lidocaine-induced $\mathrm{PNB}$ produced CPP in incised, but not sham, rats (Fig. 1C). However, CPP was not observed after PNB in rats with bilateral rACC microinjections of the opioid receptor antagonist naloxone ( $3 \mu \mathrm{g}, 10 \mathrm{~min}$ before PNB; Fig. 1C). A two-way ANOVA showed a significant effect of injury and ACC drug $\left(n=13-23\right.$; injury, $F_{(1,62)}=5.102$, $p=0.0274$; drug, $F_{(1,62)}=4.237, p=0.0438$; Bonferroni's comparison for naloxone vs saline in incised rats, $\left.{ }^{*} p<0.05\right)$. Additionally, in a separate group of rats, in vivo microdialysis demonstrated increased levels of NAc DA after PNB in incised animals pretreated with rACC saline (Fig. 1D). PNB-induced increase in NAc DA was blocked by pretreatment of rats with rACC naloxone ( $3 \mu \mathrm{g}, 10 \mathrm{~min}$ before PNB; Fig. 1D). The effect of naloxone was statistically significant, as confirmed by a two-way ANOVA $\left(n=5-10\right.$; interaction, $F_{(1,23)}=4.744, p=0.0399$; Bonferroni's comparison for naloxone vs saline in incised rats, $\left.{ }^{\star} p<0.05\right)$.

These observations were extended in a model of chronic neuropathic pain produced by spinal nerve ligation (SNL). Intrathecal clonidine $(10 \mu \mathrm{g})$ produced significant preference only in SNL rats pretreated with rACC saline but not naloxone as demonstrated by a two-way ANOVA $\left(n=13-14\right.$; interaction, $F_{(1,49)}=$ 4.994, $p=0.0300$; Bonferroni's comparison for naloxone vs saline in SNL rats, ${ }^{* *} p<0.01$; Fig. $1 G$ ). In a separate group of rats pretreated with rACC saline, intrathecal administration of clonidine $(10 \mu \mathrm{g})$ produced NAc DA efflux selectively in injured rats (Fig. $1 H$ ). This effect was abolished by intra-rACC naloxone pretreatment ( $3 \mu \mathrm{g}, 10 \mathrm{~min}$ before intrathecal clonidine) as shown by a two-way ANOVA $\left(n=8-11\right.$; interaction, $F_{(1,31)}=4.971$, $p=0.0332$; Bonferroni's comparison for naloxone vs saline in SNL rats, ${ }^{* *} p<0.01$; Fig. $\left.1 H\right)$. The same naloxone treatment in the rACC had no effect on evoked thresholds and did not interfere with the reversal of evoked hypersensitivity by PNB or intrathecal clonidine in incised or SNL rats, respectively (Figs. $1 B, E, F)$. Microinjection of rACC naloxone alone in SNL rats did not produce CPP (difference score, $6 \pm 60 \mathrm{~s} ; n=7$ ).

\section{Ablation of MOR-expressing neurons in the rACC blocks behavioral and neurochemical consequences of pain relief} The essential role of opioid receptors in the rACC for pain relief reward was further confirmed by selective loss of neurons expressing the MOR in this region using microinjection of the cytotoxic ribosome inhibitor Derm-SAP (Porreca et al., 2001). Bilateral rACC administration of Derm-SAP (1.5 pmol), compared with unconjugated SAP, 28-32 d before testing resulted in selective ablation of MOR-expressing neurons as demonstrated previously (Porreca et al., 2001) and confirmed immunohistochemically by the lack of MOR staining in brain sections at the location of Derm-SAP injection (Fig. $2 A-E$ ). Spinal clonidine 
ACC naloxone

A

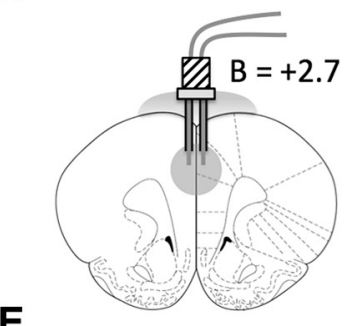

E

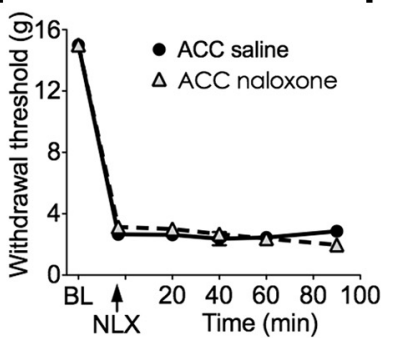

B
Hypersensitivity
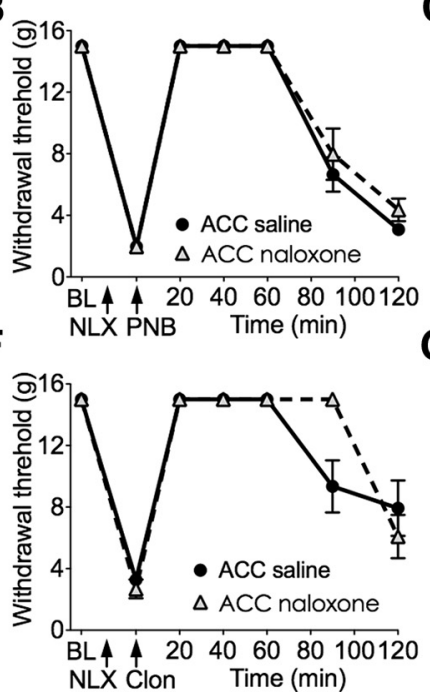

CPP

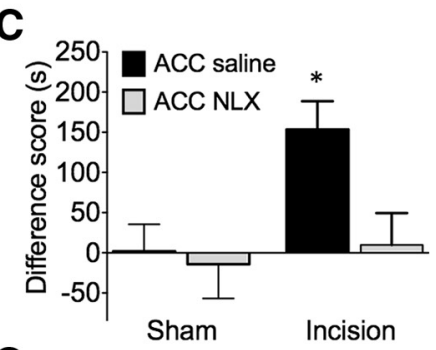

G

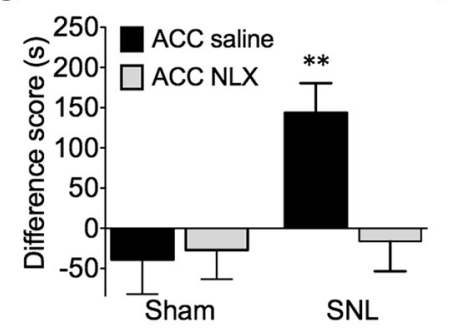

DA release

D

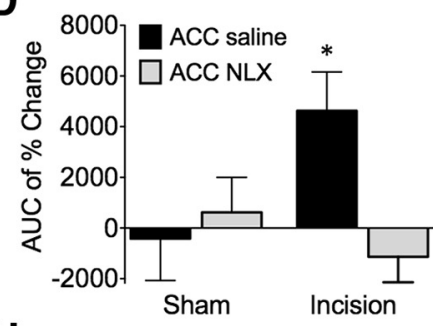

H

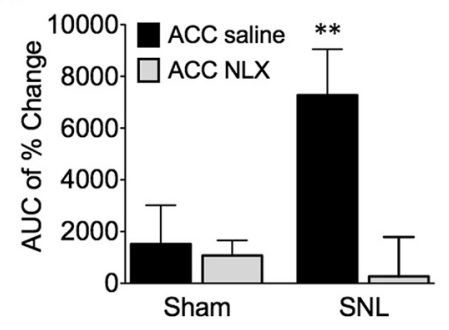

Figure 1. Blockade of opioid signaling in the rACC with naloxone prevents pain relief-induced CPP and NAC DA release in animals with incisional or neuropathic pain without altering evoked hypersensitivity. $\boldsymbol{A}$, The rACC injection site for saline or naloxone (NLX; $3 \mu \mathrm{g}, 10 \mathrm{~min}$ before testing). $\boldsymbol{B}$, In rats with incisional injury, administration of saline or naloxone in the rACC had no effects on tactile hypersensitivity and its reversal by PNB with lidocaine injection into the popliteal fossa of the injured limb $(n=6)$. C, PNB produced significant preference only in incised rats pretreated with rACC saline but not naloxone $(n=13-23)$. $D$, In incised rats, rACC naloxone abolished PNB-induced NAC DA release $(n=5-10)$. $E$, In SNL rats, rACC saline or naloxone had no effect on tactile thresholds $(n=6-7) . \boldsymbol{F}$, Neither treatment altered intrathecal clonidine-mediated reversal of tactile hypersensitivity $(n=6-7) . \mathbf{G}$, Intrathecal clonidine produced significant preference only in SNL rats pretreated with rACC saline but not naloxone $(n=13-14)$. $\boldsymbol{H}$, In SNL rats, rACC naloxone blocked intrathecal clonidine-induced DA release $(n=8-11)$. Two-way ANOVA with Bonferroni's comparison: ${ }^{*} p<0.05,{ }^{* *} p<0.01$. Data are means \pm SEMs.

ACC Derm-SAP
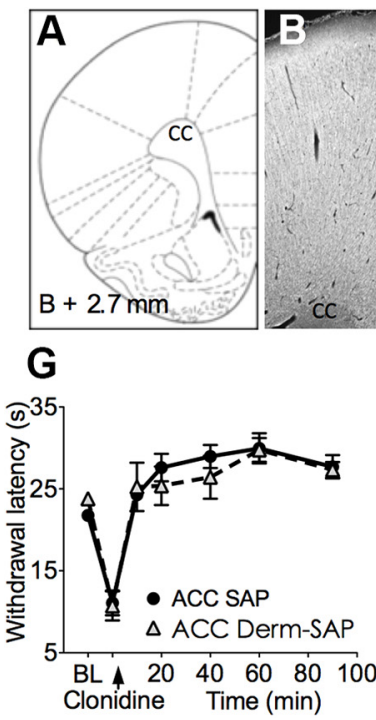
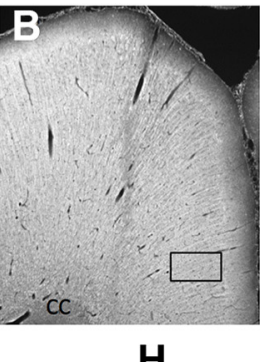
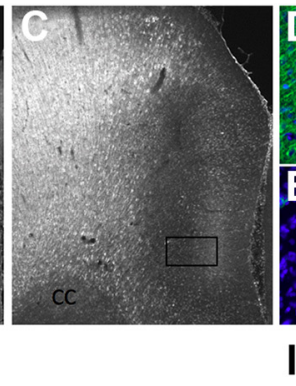

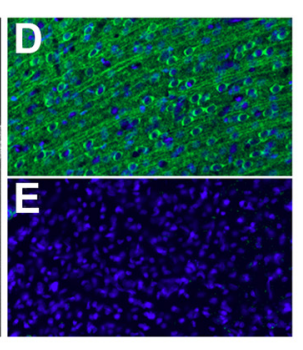

CPP

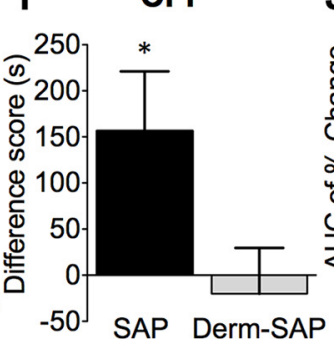

CPP to cocaine
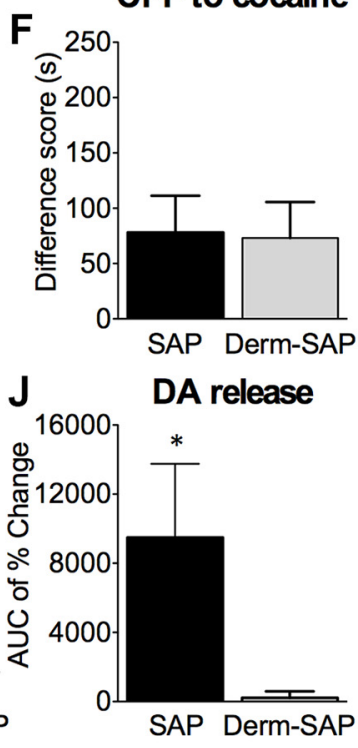

Figure 2. Ablation of MOR-expressing neurons in the rACC with Derm-SAP prevents pain relief-induced CPP and DA release in injured rats with no effects on evoked hypersensitivity. $A$, Derm-SAP or blank SAP (1.5 pmol) was administered in the rACC $28-32 \mathrm{~d}$ before experimentation. Coronal brain sections at the level of the rACC were labeled with a rabbit polyclonal anti-MOR antibody. Micrographs demonstrate lack of MOR staining in the rACC of Derm-SAP-pretreated rats ( $\boldsymbol{C}$ but not in SAP animals $(\boldsymbol{B})$. $\boldsymbol{D}$ and $\boldsymbol{E}$ show higher-magnification $(20 \times$ objective) images of the rectangular areas outlined in $\boldsymbol{B}$ and $\boldsymbol{C}$, respectively; MOR-positive neurons are in green, and DAPI nuclear staining is in blue. Images were acquired and processed using identical settings. $\boldsymbol{F}$, Derm-SAP ablation does not interfere with cocaine-induced CPP, demonstrating that the deficit in MOR signaling in the rACC does not influence the animals' ability to learn and experience cocaine reward $(n=21-22)$. $G$, In SNL rats, rACC SAP or Derm-SAP did not block the development of thermal hyperalgesia nor its reversal by spinal clonidine $(n=5-6)$. H, SAP or Derm-SAP did not block tactile allodynia or its reversal by spinal clonidine $(n=5-9)$. I, Spinal clonidine produced significant preference in SAP-treated but not in Derm-SAP-treated SNL rats $(n=11-14) . J$, In SNL rats, ablation of MOR neurons abolished intrathecal clonidine-induced DA release $(n=8)$. Student's $t$ test: ${ }^{*} p<0.05$. Data are means \pm SEMs.

produced place preference in SAP-treated but not in Derm-SAPtreated SNL rats. A Student's $t$ test confirmed that the difference between groups is significant $\left(n=11-14,{ }^{*} p<0.05, t_{(23)}=2.064\right.$; Fig. 2I). Moreover, in SNL rats, ablation of MOR neurons abolished intrathecal clonidine-induced DA release $\left(n=8,{ }^{*} p=\right.$
$0.048, t_{(14)}=2.168$; Fig. $\left.2 J\right)$. Derm-SAP pretreatment had no effect on baseline evoked thermal and tactile hypersensitivity or the reversal of these evoked responses by intrathecal clonidine in SNL-treated rats (Fig. 2G,H). Additionally, Derm-SAP lesion did not interfere with the CPP elicited by systemic administration of 

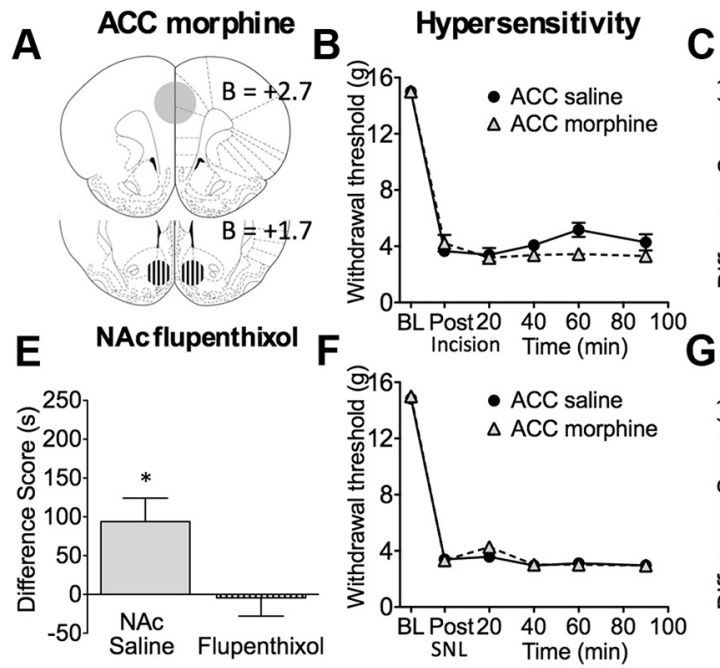
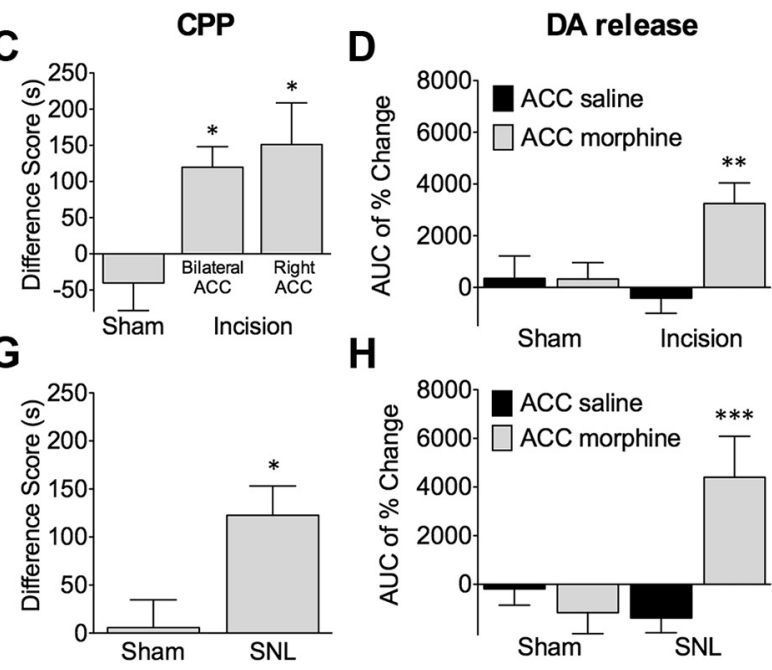

Figure 3. Administration of morphine in the rACC relieves pain. $A$, The rACC injection site for morphine ( $20 \mu \mathrm{g} / \mathrm{site}$ ) and the NAc injection site for $\alpha$-flupenthixol (3 $\mu \mathrm{g} /$ site). $\boldsymbol{B}$, In rats with postsurgical pain, bilateral administration of morphine $(20 \mu \mathrm{g})$ in the rACC had no effect on tactile hyperalgesia $(n=7-8)$. C, Bilateral (20 $\mu \mathrm{g})$ or contralateral (20 $\mu \mathrm{g}$; right side) injections of morphine in the rACC produced CPP in incised rats $(n=11-39)$. $\boldsymbol{D}$, Contralateral rACC morphine produced NAC DA release in incised rats $(n=8-15)$. $\boldsymbol{F}$, Rats with SNL developed tactile hypersensitivity that was not reversed by bilateral rACC morphine $(n=12-17)$. G, In neuropathic but not sham rats, bilateral administration of morphine into the rACC produced CPP ( $n=16-21)$. $\boldsymbol{H}$, In neuropathic rats, bilateral morphine administration into the rACC elicited NACDA release $(n=9-10)$. $\boldsymbol{E}$, CPP induced by bilateral $\mathrm{rACC}$ morphine was abolished by pretreatment in the NAc with bilateral $\alpha$-flupenthixol (3 $\mu \mathrm{g}, 10$ min before; $n=15-16) .{ }^{*} p<0.05,{ }^{* *} p<0.01,{ }^{* * *} p<0.001$. Data are means \pm SEMs.

cocaine (Fig. $2 F$ ), indicating that ablation of MOR-expressing neurons does not impede associative learning. Results presented in Figures 1 and 2 demonstrate that opioid receptors expressed on neurons in the rACC are necessary for activation of the brain motivation/reward circuits and motivated behavior after relief of pain with non-opioid treatments and implicate endogenous opioid neurotransmission within the $\mathrm{rACC}$ in reward from pain relief.

\section{Opioid neurotransmission in the rACC elicits CPP in injured animals through release of DA in the NAc}

To examine whether opioid signaling within the rACC activates reward circuits selectively in conditions of pain, we measured $\mathrm{CPP}$ and NAc DA release after microinjection of morphine into the rACC of injured or sham-operated animals. In rats with postsurgical injury, bilateral (20 $\mu \mathrm{g} / \mathrm{side})$ or contralateral $(20 \mu \mathrm{g}$; right side) injections of morphine in the rACC produced CPP. One-way ANOVA confirmed that the difference between groups was significant $\left(n=11-39, p=0.0173, F_{(2,59)}=4.347\right.$, Tukey's test, ${ }^{*} p<0.05$; Fig. $3 C$ ). In vivo microdialysis experiments in freely moving animals demonstrated that contralateral rACC morphine elicited DA efflux in the NAc $(n=8-15$; two-way ANOVA; interaction, $F_{(1,31)}=6.119, p=0.0178$; Bonferroni's comparison: ACC saline vs morphine in incised rats, ${ }^{*} p<0.01$; Fig. 3D). Bilateral rACC morphine did not influence evoked tactile hyperalgesia in incised rats (Fig. 3B).

Parallel to the findings in incised animals, rACC administration of morphine in rats with neuropathic pain also produced CPP (Fig. $3 G$ ) and elicited NAc DA release (Fig. $3 H$ ) without affecting evoked pain responses (Fig. 3F). A Student's $t$ test demonstrated that CPP difference scores were significantly elevated in SNL compared with sham rats $\left(n=10-21,{ }^{\star} p=0.0103, t_{(35)}=\right.$ 2.710). A two-way ANOVA showed a significant increase in DA release in SNL rats $\left(n=9-10\right.$; interaction: $F_{(1,34)}=10.95, p=$ 0.0022; Bonferroni's comparison: ACC saline vs morphine in SNL rats, ${ }^{* *} p<0.001$ ). Of 83 rats with incision (59 rats) or SNL (24 rats) surgery receiving bilateral or contralateral rACC morphine injections, 11 animals were excluded as a result of incorrect cannula placement. The average CPP difference score for these rats was $-1.9 \pm 34 \mathrm{~s}(n=11)$. Additionally, in SNL animals, bilateral injections of the same dose of morphine $(20 \mu \mathrm{g} / 0.5 \mu \mathrm{l} /$ site) in the caudal ACC (AP, bregma, $+0.2 \mathrm{~mm}$; ML, midline, \pm 0.6 ; DV, skull, $-2.6 \mathrm{~mm}$ ) did not produce CPP (difference score, $19.6 \pm 33 \mathrm{~s} ; n=18)$. These findings demonstrate specific effects of morphine on CPP in the rACC.

The finding that CPP and DA efflux were not observed in sham incision or sham SNL rats suggests that rACC opioids elicit reward only in an injured condition. Importantly, we further determined whether opioid neurotransmission in the rACC regulates behavior by modulating dopaminergic signaling in the NAc. Significant CPP induced by bilateral rACC morphine treatment was observed in SNL rats pretreated with NAc saline. Notably, CPP was abolished by bilateral NAc $\alpha$-flupenthixol ( $3 \mu \mathrm{g}$, 10 min before rACC injection), as shown by a significant difference between the two groups $\left(n=15-16,{ }^{\star} p=0.0149, t_{(29)}=\right.$ 2.588; Fig. 3E). Collectively, these data reveal that activation of rACC opioid receptors only in animals with injury, and presumably with ongoing pain, is sufficient to stimulate DA signaling in reward circuits and to motivate behavior. Moreover, NAc DA signaling is required for rACC morphine-induced $\mathrm{CPP}$, revealing the modulatory influence of the rACC on the reward circuit in injured states.

\section{Systemic morphine can preferentially induce CPP and NAc} DA release in SNL rats

We investigated whether systemically administered morphine could selectively activate reward circuits in injured animals. The intravenous route of morphine administration was selected because of the fast onset of effect, allowing the animals to learn to associate the chamber with the onset of pain relief. SNL surgery produced tactile hypersensitivity that was reversed by intravenous administration of morphine in a dose- and time-dependent manner (Fig. 4A,B). Morphine (4 mg/kg) produced full reversal of tactile hypersensitivity in SNL rats $\left(n=5-7, p<0.001, F_{(4,25)}\right.$ $=17.81)$. This dose also elicited CPP in both sham and SNL rats (Fig. 4C). In contrast, administration of morphine at a dose (0.5 $\mathrm{mg} / \mathrm{kg}$ ) that did not reverse tactile hypersensitivity induced significant CPP only in SNL but not sham rats (Fig. 4C). However, 
A

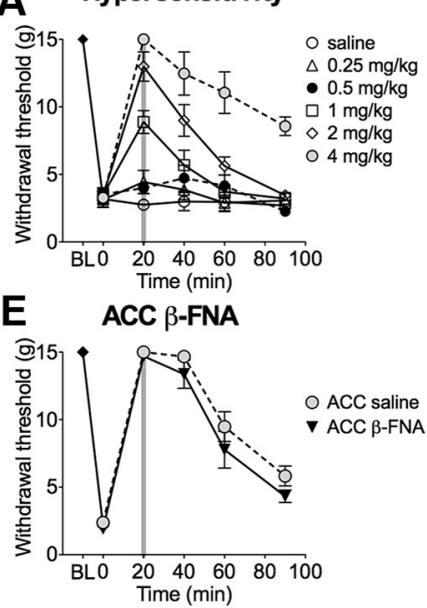

B

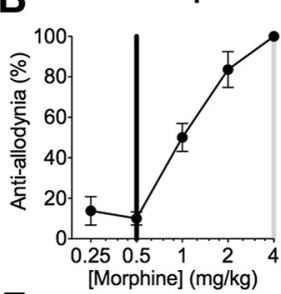

$\mathbf{F}$

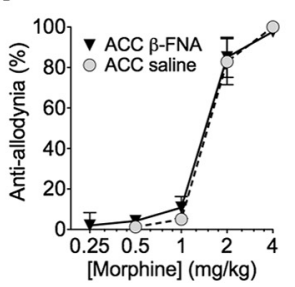

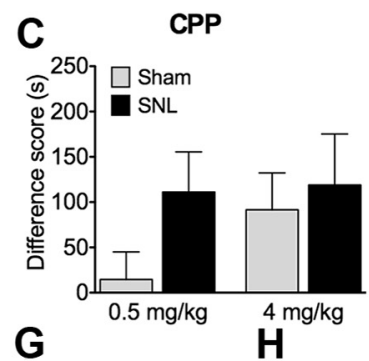
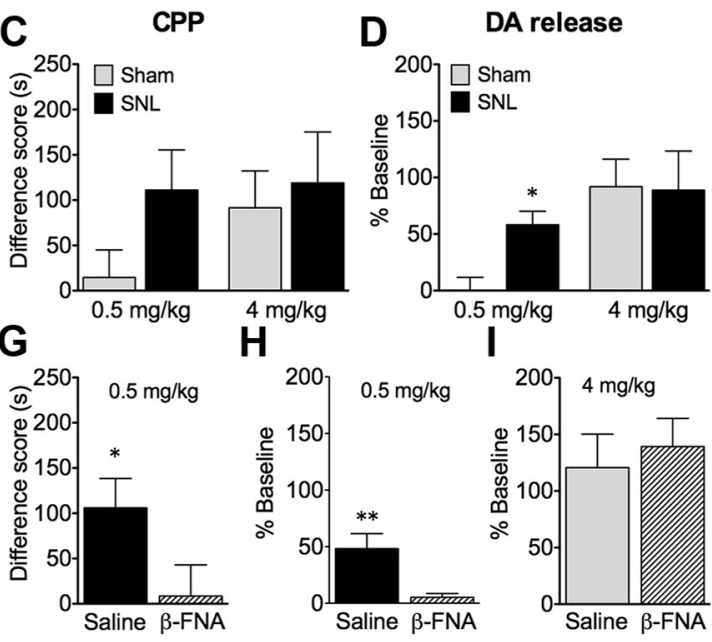

Figure 4. ACC $\beta$-FNA pretreatment blocks the effects of morphine on affective but not sensory aspects of pain. $A$, Intravenous administration of morphine time and dose dependently reversed tactile hypersensitivity $(n=5-7): 4.0 \mathrm{mg} / \mathrm{kg}$ morphine significantly attenuated tactile hypersensitivity at all time points $(n=5-7)$, whereas $0.5 \mathrm{mg} / \mathrm{kg}$ morphine had no significant effect on paw-withdrawal thresholds. $B$, The dose-response curve was calculated at $20 \mathrm{~min}$ after morphine. $C$, Morphine at $0.5 \mathrm{mg} / \mathrm{kg}$ produced CPP only in SNL but not sham rats; $4.0 \mathrm{mg} / \mathrm{kg}$ morphine produced CPP in both sham rats $(n=21-30)$. D. Morphine at $0.5 \mathrm{mg} / \mathrm{kg}$ elicited NAC DA release in SNL animals but not in sham-operated controls, whereas $4.0 \mathrm{mg} / \mathrm{kg}$ morphine produced NAC DA release in both sham and SNL animals $(n=10-11)$.E, SNL rats were pretreated $20-24 \mathrm{~h}$ before testing with bilateral $\beta$-FNA $(3 \mu \mathrm{g})$ or saline in the rACC. Morphine at $4 \mathrm{mg} / \mathrm{kg}$ significantly elevated paw-withdrawal thresholds in both groups $(n=5-6) . F$, The dose-response curves were calculated at 20 min after morphine. $\mathbf{G}$, In SNL animals pretreated with rACC saline, $0.5 \mathrm{mg} / \mathrm{kg}$ morphine elicited CPP, which was significantly attenuated in rACC $\beta$-FNA pretreated rats $(n=20-27)$. $\boldsymbol{H}$, In SNL animals receiving $0.5 \mathrm{mg} / \mathrm{kg}$ morphine, pretreatment with rACC $\beta$-FNA, but not saline, abolished DA release $(n=11)$. I, In sham-operated rats morphine $(4 \mathrm{mg} / \mathrm{kg})$ mediated DA efflux was not affected by pretreatment with either saline or $\beta$-FNA $(n=7-9) .{ }^{*} p<0.05,{ }^{* *} p<0.01$. Data are means \pm SEMs.

the difference between groups did not reach significance by twoway ANOVA. In addition, $4 \mathrm{mg} / \mathrm{kg}$ morphine increased DA levels in the NAc in both sham and SNL groups of rats, whereas 0.5 $\mathrm{mg} / \mathrm{kg}$ morphine elicited NAc DA release only in SNL animals but not in sham-operated controls (Fig. 4D). Two-way ANOVA with Bonferroni's post hoc test demonstrated a significant effect of the morphine dose in sham animals $\left(n=10-11, F_{(1,37)}=7.188\right.$, $p=0.0109$; Bonferroni's comparison: $0.5 \mathrm{vs} 4 \mathrm{mg} / \mathrm{kg}$ morphine in sham rats, $\left.{ }^{\star} p<0.05\right)$. These results suggest that doses of morphine $(0.5 \mathrm{mg} / \mathrm{kg})$ that are not rewarding in sham-operated rats become rewarding in injured rats, presumably because of pain relief.

The anti-aversive effects of morphine are abolished by pharmacological blockade of opioid receptors in the rACC Subsequently, we investigated the possibility that opioid receptors within the rACC mediate the effects of systemic morphine on the affective/motivational dimension of pain. SNL or sham animals were pretreated with bilateral rACC microinjections of the irreversible MOR antagonist $\beta$-funaltrexamine $(\beta$-FNA; $3 \mu \mathrm{g}$, $24 \mathrm{~h}$ before testing), and mechanical allodynia, CPP, and NAc microdialysis in response to intravenous morphine administration were evaluated. The anti-allodynic dose response of morphine did not differ between SNL animals receiving rACC $\beta$-FNA or saline (Fig. $4 F$ ). Morphine at $4 \mathrm{mg} / \mathrm{kg}$ significantly elevated paw-withdrawal thresholds in both groups (Fig. 4E). Two-way ANOVA showed a significant time effect of intravenous morphine treatment but no significant difference between ACC pretreatment groups ( $n=10-11$; time: $F_{(5,95)}=155.4, p<0.0001$; Fig. $4 E$ ). SNL animals receiving rACC saline demonstrated CPP to the sub-analgesic $(0.5 \mathrm{mg} / \mathrm{kg})$ dose of morphine, which was significantly attenuated in rACC $\beta$-FNA-pretreated rats $(n=$ $20-27,{ }^{\star} p=0.0478, t_{(45)}=2.035$; Fig. $\left.4 G\right)$. Likewise, in SNL animals receiving $0.5 \mathrm{mg} / \mathrm{kg}$ morphine, pretreatment with $\mathrm{rACC}$ $\beta$-FNA, but not saline, abolished DA release $\left(n=11,{ }^{* *} p=0.005\right.$, $t_{(20)}=3.128$; Fig. $\left.4 H\right)$. This suggests that blockade of opioid signaling in the rACC prevented the anti-aversive effects of morphine in SNL rats. However, in sham animals, rACC pretreatment with $\beta$-FNA had no effect on DA release elicited by a $4 \mathrm{mg} / \mathrm{kg}$ dose of morphine (Fig. $4 I$ ), indicating that the intrinsically rewarding effects of morphine are not dependent on MORs in the rACC.

\section{Discussion}

In this study, we investigated the hypothesis that opioid activity in the rACC is necessary for the negative reinforcement produced by relief of ongoing pain. We showed that microinjection of naloxone, a selective opioid antagonist that acts at multiple opioid receptor subtypes, in the rACC prevented CPP to non-opioid analgesic treatments, including PNB in incised rats or intrathecal clonidine in neuropathic rats. In contrast, naloxone pretreatment in the rACC had no effect on the ability of these treatments to reverse mechanical allodynia seen in the injured rats. Selective ablation of MOR-expressing neurons in the rACC also inhibited behavioral manifestations of pain relief without altering evoked responses. Thus, altogether, our CPP results using two rat pain models and two different approaches to inhibit opioid signaling in the ACC provide strong evidence for the requirement of endogenous opioid signaling and MOR-expressing neurons in the rACC for relief of ongoing pain. Conversely, administration of morphine in the rACC showed that these circuits can be engaged to elicit CPP without altering allodynia. The results are consistent with human data indicating the role of the ACC opioids in modulation of aversive features of pain. Activation of endogenous opioid systems in the ACC has been observed during placebo analgesia (Wager et al., 2007; Zubieta and Stohler, 2009) and during sustained experimental pain (Zubieta et al., 2001). Human neuroimaging demonstrates engagement of ACC circuits and reduction of the affective component of pain without change in pain intensity after hypnotic suggestions (Rainville, 2002) and during positive emotional states (Villemure and Bushnell, 2009). A previous study in neuropathic rats showed that ACC microinjection of morphine is sufficient to decrease aversiveness of evoked stimuli without modulation of evoked responses (LaGraize et al., 2006). Our study now demonstrates that opioid 
signaling in the ACC is also necessary for negative reinforcement attributable to relief of ongoing pain.

Previous investigations in our laboratory established that activation of the DA mesolimbic reward system is required for pain relief-induced CPP (Navratilova et al., 2012; Xie et al., 2014). Here, we demonstrate that, in the setting of pain, multiple rACC manipulations that block (naloxone, Derm-SAP) or elicit (morphine) CPP also block or elicit NAc DA release. Therefore, opioid signaling in the rACC is essential for NAc DA release and consequent pain relief-induced negative reinforcement. This conclusion is consistent with PET studies of placebo analgesia in humans revealing a positive correlation between endogenous opioid activity in the rACC and DA activity in the NAc (Scott et al., 2008). The finding that blockade of DA receptors in the NAc with flupenthixol precludes rACC morphine-elicited CPP establishes directionality of the modulatory control of behavior from the rACC to NAc. Strong direct neuronal projections from the ACC to the NAc have been demonstrated anatomically (Gorelova and Yang, 1997); additional indirect pathways may support a functional link between these two regions. In the present study, rACC morphine-induced DA release and CPP was specific to the tonic aversive pain state and was not observed in pain-free conditions. This is in sharp contrast to the effects of microinjections into the ventral tegmental area (VTA), the origin of mesolimbic dopaminergic neurons, in which morphine causes CPP in naive animals (Olmstead and Franklin, 1997). In pain states, pharmacological or endogenous opioid signaling in the rACC activates DA reward circuitry and promotes reward.

We additionally examined whether systemically administered opioids use the same mechanisms to alleviate pain unpleasantness and subsequently elicit reward from pain relief. Opiates have been shown to preferentially reduce affective but not sensory visual analog scale responses to either acute noxious stimulus in subjects or chronic neuropathic pain in patients (Price et al., 1985; Kupers et al., 1991). Moreover, low doses of opiates inhibit pain-related BOLD-fMRI activations in brain areas associated with affective pain processing, whereas higher doses are required for complete inhibition in areas processing sensory dimensions of pain (Oertel et al., 2008). Differential effects of morphine on the affective and sensory dimensions of pain have been suggested previously in preclinical studies (Hummel et al., 2008; van der Kam et al., 2008; Cahill et al., 2013), but the underlying mechanisms are not known. We found that, in rats with neuropathic pain, morphine at a dose that did not alleviate tactile allodynia elicited CPP and NAc DA release, suggesting selective modulation of affective features of pain to elicit reward. Critically, the same dose was not rewarding in uninjured animals, demonstrating a separation of the rewarding effects of pain relief from intrinsically rewarding effects of morphine. Morphine, like other addictive drugs, is rewarding in the normal state, in part, because of its ability to directly activate the mesolimbic DA reward pathway from the VTA to the NAc. Opioid receptors in this pathway are required for the rewarding effects of morphine (Olmstead and Franklin, 1997; Cui et al., 2014). Here, using blockade of opioid receptors with intra-rACC $\beta$-FNA, we demonstrate that the anti-aversive effects of morphine (e.g., reward from pain relief) are mediated by opioid circuits in the rACC. In contrast, we show that opioid signaling in the rACC is not required for reward elicited by high doses of morphine that mediate reward in the non-painful state. Therefore, anti-aversive and rewarding effects of morphine can be dissociated both pharmacologically and anatomically. The anti-aversive effects of low doses of morphine depend on the engagement of opioid receptors in the rACC, whereas rewarding effects that require almost an order of magnitude higher dose do not involve opioid receptors in this circuit.

The precise mechanisms by which endogenous opioids regulate nociceptive activity within the ACC is not clear. Opioid peptides and receptors are highly expressed in the ACC, and opioid signaling in this region is implicated in modulating affective aspects of pain. Enkephalinergic neurons are distributed broadly within all laminae in the ACC (Mukamel et al., 2005). Likewise, both MORs and $\delta$ opioid receptors (DORs) are present throughout the cingulate cortex, with increased expression of the MOR in the superficial layer (Vogt et al., 1995). Although virtually all DORs are expressed by cortical neurons, MORs are expressed by both cortical neurons and afferent axons from subcortical regions. Presynaptic MORs have been found primarily on thalamic axonal projections to the ACC (Vogt et al., 1995). Hence, it may be reasonable to suggest that endogenous opioids could regulate nociceptive activity in the ACC by inhibiting glutamate release from thalamocortical afferents or by modulating the activity of cortical interneurons and efferent projection neurons. Additional experimentation will be required to explore these possibilities.

Our data demonstrate the essential role of ACC opioid activity for relief of ongoing pain produced by local non-opioid treatments. This conclusion is supported by behavioral and neurochemical measures using several different approaches and is consistent with findings from human neuroimaging. We show that endogenous opioid release in the rACC is not only sufficient but necessary for relief of the ongoing aversive state associated with pain. Additionally, our findings suggest that ACC opioid signaling elicits NAc DA efflux, promoting reward of pain relief. Moreover, doses of systemically administered opioids that are not reinforcing in naive animals act in the ACC to relieve pain aversiveness and facilitate reward. These findings anatomically and pharmacologically separate opioid mechanisms promoting pain relief and addiction. Opioid signaling in the ACC may represent a general mechanism of pain modulation that can serve as a biomarker of analgesic efficacy and facilitate drug discovery for pain therapeutics.

\section{References}

Acworth I, Cunningham ML (1999) The measurement of monoamine neurotransmitters in microdialysis perfusates using HPLC-ECD. Methods Mol Med 22:219-236. CrossRef Medline

Apkarian AV, Bushnell MC, Treede RD, Zubieta JK (2005) Human brain mechanisms of pain perception and regulation in health and disease. Eur J Pain 9:463-484. CrossRef Medline

Becerra L, Navratilova E, Porreca F, Borsook D (2013) Analogous responses in the nucleus accumbens and cingulate cortex to pain onset (aversion) and offset (relief) in rats and humans. J Neurophysiol 110:1221-1226. CrossRef Medline

Becker S, Gandhi W, Schweinhardt P (2012) Cerebral interactions of pain and reward and their relevance for chronic pain. Neurosci Lett 520:182187. CrossRef Medline

Brennan TJ, Vandermeulen EP, Gebhart GF (1996) Characterization of a rat model of incisional pain. Pain 64:493-501. CrossRef Medline

Bushnell MC, Ceko M, Low LA (2013) Cognitive and emotional control of pain and its disruption in chronic pain. Nat Rev Neurosci 14:502-511. CrossRef Medline

Cahill CM, Xue L, Grenier P, Magnussen C, Lecour S, Olmstead MC (2013) Changes in morphine reward in a model of neuropathic pain. Behav Pharmacol 24:207-213. CrossRef Medline

Chaplan SR, Bach FW, Pogrel JW, Chung JM, Yaksh TL (1994) Quantitative assessment of tactile allodynia in the rat paw. J Neurosci Methods 53:55-63. CrossRef Medline

Cui Y, Ostlund SB, James AS, Park CS, Ge W, Roberts KW, Mittal N, Murphy NP, Cepeda C, Kieffer BL, Levine MS, Jentsch JD, Walwyn WM, Sun YE, Evans CJ, Maidment NT, Yang XW (2014) Targeted expression of muopioid receptors in a subset of striatal direct-pathway neurons restores opiate reward. Nat Neurosci 17:254-261. CrossRef Medline 
Cunningham CL, Ferree NK, Howard MA (2003) Apparatus bias and place conditioning with ethanol in mice. Psychopharmacology (Berl) 170:409422. CrossRef Medline

Gorelova N, Yang CR (1997) The course of neural projection from the prefrontal cortex to the nucleus accumbens in the rat. Neuroscience 76:689706. Medline

Hargreaves K, Dubner R, Brown F, Flores C, Joris J (1988) A new and sensitive method for measuring thermal nociception in cutaneous hyperalgesia. Pain 32:77-88. Medline

Hsieh JC, Belfrage M, Stone-Elander S, Hansson P, Ingvar M (1995) Central representation of chronic ongoing neuropathic pain studied by positron emission tomography. Pain 63:225-236. Medline

Hubbard KE, Wells A, Owens TS, Tagen M, Fraga CH, Stewart CF (2010) Determination of dopamine, serotonin, and their metabolites in pediatric cerebrospinal fluid by isocratic high performance liquid chromatography coupled with electrochemical detection. Biomed Chromatogr 24:626-631. Medline

Hummel M, Lu P, Cummons TA, Whiteside GT (2008) The persistence of a long-term negative affective state following the induction of either acute or chronic pain. Pain 140:436-445. CrossRef Medline

Johansen JP, Fields HL (2004) Glutamatergic activation of anterior cingulate cortex produces an aversive teaching signal. Nat Neurosci 7:398-403. CrossRef Medline

Johansen JP, Fields HL, Manning BH (2001) The affective component of pain in rodents: direct evidence for a contribution of the anterior cingulate cortex. Proc Natl Acad Sci USA 98:8077-8082. CrossRef Medline

Kadiyala RK, Ramirez A, Taylor AE, Saltzman CL, Cassell MD (2005) The blood supply of the common peroneal nerve in the popliteal fossa. J Bone Joint Surg Br 87:337-342. CrossRef Medline

Kim SH, Chung JM (1992) An experimental model for peripheral neuropathy produced by segmental spinal nerve ligation in the rat. Pain 50:355363. CrossRef Medline

King T, Rao S, Vanderah T, Chen Q, Vardanyan A, Porreca F (2006) Differential blockade of nerve injury-induced shift in weight bearing and thermal and tactile hypersensitivity by milnacipran. J Pain 7:513-520. CrossRef Medline

King T, Vera-Portocarrero L, Gutierrez T, Vanderah TW, Dussor G, Lai J, Fields HL, Porreca F (2009) Unmasking the tonic-aversive state in neuropathic pain. Nat Neurosci 12:1364-1366. CrossRef Medline

King T, Qu C, Okun A, Melemedjian OK, Mandell EK, Maskaykina IY, Navratilova E, Dussor GO, Ghosh S, Price TJ, Porreca F (2012) Contribution of PKMzeta-dependent and independent amplification to components of experimental neuropathic pain. Pain 153:1263-1273. CrossRef Medline

Kuo CC, Yen CT (2005) Comparison of anterior cingulate and primary somatosensory neuronal responses to noxious laser-heat stimuli in conscious, behaving rats. J Neurophysiol 94:1825-1836. CrossRef Medline

Kupers RC, Konings H, Adriaensen H, Gybels JM (1991) Morphine differentially affects the sensory and affective pain ratings in neurogenic and idiopathic forms of pain. Pain 47:5-12. CrossRef Medline

LaGraize SC, Labuda CJ, Rutledge MA, Jackson RL, Fuchs PN (2004) Differential effect of anterior cingulate cortex lesion on mechanical hypersensitivity and escape/avoidance behavior in an animal model of neuropathic pain. Exp Neurol 188:139-148. CrossRef Medline

LaGraize SC, Borzan J, Peng YB, Fuchs PN (2006) Selective regulation of pain affect following activation of the opioid anterior cingulate cortex system. Exp Neurol 197:22-30. CrossRef Medline

Leknes S, Tracey I (2008) A common neurobiology for pain and pleasure. Nat Rev Neurosci 9:314-320. CrossRef Medline

Leknes S, Lee M, Berna C, Andersson J, Tracey I (2011) Relief as a reward: hedonic and neural responses to safety from pain. PLoS One 6:e17870. CrossRef Medline

Mitchell JM, Margolis EB, Coker AR, Allen DC, Fields HL (2014) Intra-VTA deltorphin, but not DPDPE, induces place preference in ethanol-drinking rats: distinct DOR-1 and DOR-2 mechanisms control ethanol consumption and reward. Alcohol Clin Exp Res 38:195-203. CrossRef Medline

Mukamel R, Gelbard H, Arieli A, Hasson U, Fried I, Malach R (2005) Coupling between neuronal firing, field potentials, and FMRI in human auditory cortex. Science 309:951-954. CrossRef Medline

Navratilova E, Xie JY, Okun A, Qu C, Eyde N, Ci S, Ossipov MH, King T, Fields HL, Porreca F (2012) Pain relief produces negative reinforcement through activation of mesolimbic reward-valuation circuitry. Proc Natl Acad Sci USA 109:20709-20713. CrossRef Medline
Navratilova E, Xie JY, King T, Porreca F (2013) Evaluation of reward from pain relief. Ann N Y Acad Sci 1282:1-11. CrossRef Medline

Oertel BG, Preibisch C, Wallenhorst T, Hummel T, Geisslinger G, Lanfermann H, Lötsch J (2008) Differential opioid action on sensory and affective cerebral pain processing. Clin Pharmacol Ther 83:577-588. CrossRef Medline

Okun A, DeFelice M, Eyde N, Ren J, Mercado R, King T, Porreca F (2011) Transient inflammation-induced ongoing pain is driven by TRPV1 sensitive afferents. Mol Pain 7:4. CrossRef Medline

Olmstead MC, Franklin KB (1997) The development of a conditioned place preference to morphine: effects of microinjections into various CNS sites. Behav Neurosci 111:1324-1334. CrossRef Medline

Paxinos GW, Watson C (2007) The rat brain in stereotaxic coordinates. Amsterdam: Academic

Porreca F, Burgess SE, Gardell LR, Vanderah TW, Malan TP Jr, Ossipov MH, Lappi DA, Lai J (2001) Inhibition of neuropathic pain by selective ablation of brainstem medullary cells expressing the mu-opioid receptor. J Neurosci 21:5281-5288. Medline

Price DD, Von der Gruen A, Miller J, Rafii A, Price C (1985) A psychophysical analysis of morphine analgesia. Pain 22:261-269. CrossRef Medline

Qu C, King T, Okun A, Lai J, Fields HL, Porreca F (2011) Lesion of the rostral anterior cingulate cortex eliminates the aversiveness of spontaneous neuropathic pain following partial or complete axotomy. Pain 152: 1641-1648. CrossRef Medline

Rainville P (2002) Brain mechanisms of pain affect and pain modulation. Curr Opin Neurobiol 12:195-204. CrossRef Medline

Rainville P, Duncan GH, Price DD, Carrier B, Bushnell MC (1997) Pain affect encoded in human anterior cingulate but not somatosensory cortex. Science 277:968-971. CrossRef Medline

Scott DJ, Stohler CS, Egnatuk CM, Wang H, Koeppe RA, Zubieta JK (2008) Placebo and nocebo effects are defined by opposite opioid and dopaminergic responses. Arch Gen Psychiatry 65:220-231. CrossRef Medline

van der Kam EL, Vry JD, Schiene K, Tzschentke TM (2008) Differential effects of morphine on the affective and the sensory component of carrageenaninduced nociception in the rat. Pain 136:373-379. CrossRef Medline

Villemure C, Bushnell MC (2009) Mood influences supraspinal pain processing separately from attention. J Neurosci 29:705-715. CrossRef Medline

Vogt BA (2005) Pain and emotion interactions in subregions of the cingulate gyrus. Nat Rev Neurosci 6:533-544. CrossRef Medline

Vogt BA, Sikes RW (2000) The medial pain system, cingulate cortex, and parallel processing of nociceptive information. Prog Brain Res 122:223235. Medline

Vogt BA, Wiley RG, Jensen EL (1995) Localization of Mu and delta opioid receptors to anterior cingulate afferents and projection neurons and input/ output model of Mu regulation. Exp Neurol 135:83-92. CrossRef Medline

Wager TD, Rilling JK, Smith EE, Sokolik A, Casey KL, Davidson RJ, Kosslyn SM, Rose RM, Cohen JD (2004) Placebo-induced changes in FMRI in the anticipation and experience of pain. Science 303:1162-1167. CrossRef Medline

Wager TD, Scott DJ, Zubieta JK (2007) Placebo effects on human muopioid activity during pain. Proc Natl Acad Sci USA 104:11056-11061. CrossRef Medline

Wang JY, Luo F, Chang JY, Woodward DJ, Han JS (2003) Parallel pain processing in freely moving rats revealed by distributed neuron recording. Brain Res 992:263-271. CrossRef Medline

Willoch F, Gamringer U, Medele R, Steude U, Tölle TR (2003) Analgesia by electrostimulation of the trigeminal ganglion in patients with trigeminopathic pain: a PET activation study. Pain 103:119-130. CrossRef Medline

Xie JY, Qu C, Patwardhan A, Ossipov MH, Navratilova E, Becerra L, Borsook D, Porreca F (2014) Activation of mesocorticolimbic reward circuits for assessment of relief of ongoing pain: a potential biomarker of efficacy. Pain 155:1659-1666. CrossRef Medline

Xu J, Brennan TJ (2009) Comparison of skin incision vs. skin plus deep tissue incision on ongoing pain and spontaneous activity in dorsal horn neurons. Pain 144:329-339. CrossRef Medline

Xu J, Brennan TJ (2010) Guarding pain and spontaneous activity of nociceptors after skin versus skin plus deep tissue incision. Anesthesiology 112: 153-164. CrossRef Medline

Zubieta JK, Stohler CS (2009) Neurobiological mechanisms of placebo responses. Ann N Y Acad Sci 1156:198-210. CrossRef Medline

Zubieta JK, Smith YR, Bueller JA, Xu Y, Kilbourn MR, Jewett DM, Meyer CR, Koeppe RA, Stohler CS (2001) Regional mu opioid receptor regulation of sensory and affective dimensions of pain. Science 293:311-315. CrossRef Medline 